\title{
Bisphenol A-induced oxidative damage in the hepatic and cardiac tissues of rats: The modulatory role of sesame lignans
}

\author{
SABER M. EWEDA ${ }^{1,2}$, AL SAYEDA A. NEWAIRY ${ }^{1}$, HEBA M. ABDOU ${ }^{3}$ and ASSMAA S. GABER ${ }^{1}$ \\ ${ }^{1}$ Department of Clinical Laboratory Sciences, Faculty of Applied Medical Sciences, Taibah University, \\ Medina 42353, Kingdom of Saudi Arabia; Departments of ${ }^{2}$ Biochemistry and ${ }^{3}$ Zoology, \\ Faculty of Science, Alexandria University, Alexandria 21561, Egypt
}

Received April 27, 2018; Accepted May 31, 2019

DOI: $10.3892 /$ etm.2019.8193

\begin{abstract}
Bisphenol A (BPA) is an environmental pollutant that is widely produced throughout the world. It is primarily used in the manufacture of polycarbonate plastics, epoxy resins, paints and dental materials. BPA has been reported to promote hepatotoxicity and cardiotoxicity. The antioxidant activity of sesame lignans is well established. The current study assessed the protective efficiency of sesame lignans against BPA-induced hepatotoxicity and cardiotoxicity. Rats were divided into 4 groups: A control group, a BPA-treated group, a sesame lignans-treated group and a sesame lignans and BPA-treated group. Rats were orally administered their respective doses daily $[30 \mathrm{mg} / \mathrm{kg}$ body weight (BW) BPA and/or $20 \mathrm{mg} / \mathrm{kg}$ BW sesame lignans] for 6 weeks. Liver function tests were performed using serum of all groups. Lipid profile and antioxidant status were also measured in liver tissue of the studied groups. The results were confirmed by histopathological examination of liver and heart tissues. The oral administration of BPA was revealed to elicit significant decreases in the activities of hepatic glutathione peroxidase, glutathione reductase, superoxide dismutase and glutathione. It also significantly increased levels of malondialdehyde. Furthermore, BPA-treatment resulted in lipid accumulation, elevated activities of alanine aminotransferase, creatine kinase $\mathrm{MB}$ and lactate dehydrogenase, and histological changes of liver and heart tissues. However, the co-administration of sesame lignans and BPA attenuated hepatotoxicity, cardiotoxicity and BPA-induced histological changes. The results of the current study indicated that sesame lignans may be helpful in the development of novel natural drugs to treat hepatic and cardiovascular disorders.
\end{abstract}

Correspondence to: Dr Saber M. Eweda, Department of Clinical Laboratory Sciences, Faculty of Applied Medical Sciences, Taibah University, Janadah Bin Umayyah Road, Medina 42353, Kingdom of Saudi Arabia

E-mail: saber_eweda2003@yahoo.com

Key words: sesame lignans, Bisphenol A, oxidative stress, liver, heart

\section{Introduction}

Bisphenol A [BPA; 2,2-bis (4-hydroxyphenyl)], an environmental contaminant, is an increasingly produced worldwide chemical (1). BPA is used in the manufacture of polycarbonate plastics, epoxy resins and hard plastic bottles, which are commonly consumed products (2). Epoxy resins are used in food-contact surface lacquer coatings for cans, automobile parts and as a coating for PVC pipes (3). The increased use of these products has led to a BPA content of $>90 \%$ in various human biological fluids, including human breast milk, amniotic fluid and neonatal blood (4). The primary route of BPA exposure is via ingestion (1), but transdermal absorption and inhalation are probable secondary exposure routes, particularly in individuals who work in companies that produce BPA-based products $(3,5)$. BPA is an endocrine-disrupting substance with estrogenic and thyroid hormone-like effects (6). Several studies have reported that BPA exposure promotes hepatotoxicity and induces oxidative damage via different mechanisms $(7,8)$. Other studies have determined an association between BPA exposure and an increased risk of reproductive dysfunction, cardiovascular disease, obesity, type II diabetes and thyroid dysfunction $(6,9)$. Sesame (Sesamum indicum L.) is a crop that is produced worldwide. It has been cultivated in Asia and Africa for its high content of edible oil and protein (10) and has been used as a traditional food source in the countries of East Asia (11). Sesame oil is considered to be a superior vegetable oil, as it has a high nutritional value (12) that is therapeutically effective within 3-12 h after oral administration (13). Sesame oil decreases blood pressure, lipid profiles and lipid peroxidation, and increases enzymatic and nonenzymatic antioxidants (14). The potent antioxidant activity of sesame oil is due to its high content of polyunsaturated fatty acids and lignans (15). Sesame lignans include sesamin, sesamolin, sesamol, sesaminol, sesamolinol, pinoresinol, matairesinol, lariciresinol and episesamin, which all exhibit a broad spectrum of biological properties (16). Sesame lignans individually or in combination, exhibit different biological activities. Sesamin has been revealed to serve an important role in lipid and glucose metabolism, hypertension, anti-inflammation and free radical scavenge (17). Sesamolin promotes apoptosis, suppresses neuronal reactive oxygen species (ROS) generation and attenuates mutagenesis induced by $\mathrm{H}_{2} \mathrm{O}_{2}(18,19)$. 
Furthermore, sesaminol inhibits DNA oxidative damage, decreases low-density lipoprotein (LDL) oxidation induced by copper and inhibits membrane lipid peroxidation $(20,21)$. Yashaswini et al (22) reported that the oral administration of sesamol and sesamin modulates inflammatory and oxidative damage markers in lipopolysaccharide (LPS)-injected rats. However, to the best of our knowledge, there are no in vivo studies assessing the protective effect of sesame lignans against BPA-induced hyperlipidemia and oxidative damage. Accordingly, the aim of the current study was to investigate the modulative effects of sesame lignans against BPA-induced hepatic and cardiac toxicity in rats. This was achieved by performing liver and heart function tests, determining lipid profiles and assessing the levels of certain oxidants and antioxidants. Biochemical parameters were also confirmed via histopathological examinations of liver and heart tissue. In addition, the dorsal aorta was quantitatively analyzed.

\section{Materials and methods}

Chemicals. BPA, glutathione reductase (GR), glutathione (GSH), pyrogallol, NADPH, 2-thiobarbituric acid, 1,1,3,3-tetraethoxypropane, 5,5'-dithiobis-(2-nitrobenzoic acid) (DTNB) and bovine serum albumin were purchased from Sigma-Aldrich (Merck KGaA). All other general chemicals and kits were of analytical grade.

Extraction and purification of sesame lignans. Sesame lignans were extracted and purified as described by Reshma et al (23). Sesame oil (100 g) was mixed with methanol (1:1 w/v) in an extraction vessel. The mixture was then stirred for $10 \mathrm{~min}$ at $70^{\circ} \mathrm{C}$ and transferred into a separating funnel. Following $15 \mathrm{~min}$ of settling time, the methanolic extract was separated from the residual oil, which was subsequently stripped of solvent and subjected to 9 additional sequential extractions with fresh batches of methanol performed exactly as described above. The 10 methanolic extracts were pooled and concentrated via evaporation at $40^{\circ} \mathrm{C}$ using a rotary evaporator (Model 4622; BUCHI Rotavapor ${ }^{\mathrm{TM}}$ R-100; Thermo Fisher Scientific, Inc.). These extracts were then dispersed in petroleum ether at a ratio of 1:0.5 (w/v). The mixture was left to stand for 24-48 $\mathrm{h}$ at $4^{\circ} \mathrm{C}$ to facilitate the lignan crystallization. Lignan crystals were separated from the mixture via filtration, washed with cold petroleum ether, dried in a vacuum oven at a temperature of $40^{\circ} \mathrm{C}$ for $1 \mathrm{~h}$ and weighed.

Experimental design. A total of 40 adult male Wister albino rats (weight, 150-160 g) were obtained from the animal house of Faculty of Medicine, Alexandria University, Egypt. The design and experimental techniques of the current study were approved by the Institutional Animal Care and Use Committee (IACUC) of Alexandria University in accordance with the guidelines of the National Institutes of Health Guide for the Care and Use of Laboratory Animals. All efforts were made to minimise the suffering of rats during the experimental period. Rats were housed in stainless steel cages and provided with a basal diet and tap water ad libitum. Animals were maintained under $25^{\circ} \mathrm{C}$ and a $12 \mathrm{~h}$ light/dark cycle with relative humidity $50-60 \%$ during the experimental period. Rats were equally and randomly divided into the following four groups (each, $n=10$ ):
A control group (C-group), a BPA-treated group (B-group) that received $30 \mathrm{mg} / \mathrm{kg}$ (24), a sesame lignans-treated group (S-group) that were treated with sesame lignans (20 mg/kg) (25) and a BPA plus sesame lignans-treated group (BS-group) that received BPA (30 mg/kg) and sesame lignans $(20 \mathrm{mg} / \mathrm{kg})$. Rats were orally administered their respective doses daily for 6 weeks.

Sampling and tissue preparation. At the end of experimental period, rats were starved for $12 \mathrm{~h}$ and then deeply euthanized via an intraperitoneal injection of $100 \mathrm{mg} / \mathrm{kg}$ ketamine and $20 \mathrm{mg} / \mathrm{kg}$ xylazine. The $12 \mathrm{~h}$ fasting period prior to sampling did not cause remarkable loss of body weight or any observed adverse effects on rats. After euthanasia, $4 \mathrm{ml}$ of blood was obtained through cardiac puncture using a sterile syringe. Death was subsequently confirmed by the inhalation of $\mathrm{CO}_{2}$ from a pressurized tank at a flow rate of $25 \%$ per min followed by cervical dislocation. Serum was obtained by centrifugation of clotted blood at $1,000 \mathrm{x} \mathrm{g}$ at $25^{\circ} \mathrm{C}$ for $10 \mathrm{~min}$ and kept at $-20^{\circ} \mathrm{C}$ for lipid profiling and liver and heart function tests. Liver, heart and dorsal aorta were immediately isolated and washed with cold saline solution. Pieces of tissue were then fixed for $12 \mathrm{~h}$ with $10 \%$ formalin at $25^{\circ} \mathrm{C}$ for histological examination. Liver tissue $(0.25 \mathrm{~g})$ was subsequently homogenized individually in $5 \mathrm{ml}$ of $5 \%$ trichloroacetic acid, containing 0.003 M EDTA. The homogenate was centrifuged at $500 \mathrm{x} \mathrm{g}$ for $15 \mathrm{~min}$ at $4^{\circ} \mathrm{C}$ and the supernatants were stored at $-20^{\circ} \mathrm{C}$ for reduced $\mathrm{GSH}$ determination. Additionally, $0.5 \mathrm{~g}$ liver tissue was isolated, washed and homogenized in PBS (0.1 M; pH 7.4). The homogenate was centrifuged at $25,000 \mathrm{x}$ g for $10 \mathrm{~min}$ at $4^{\circ} \mathrm{C}$ (Hitachi Ltd.; model, EBA $12 \mathrm{R})$. Supernatants were stored in aliquots of $1 \mathrm{ml}$ at $-20^{\circ} \mathrm{C}$ for subsequent biochemical analysis.

Extraction of hepatic total lipids. Total liver lipid content was measured via gravimetric determination according to a method previously described by Folch et al (26). Half gram of liver tissue was homogenized in $5 \mathrm{ml}$ of chloroform-methanol mixture (2:1, v/v) using a Polytron homogenizer (model, TR-10; Tekmar). The solvent obtained from the extract was evaporated and the extracted lipids were reconstituted in $0.2 \mathrm{ml}$ petroleum ether and used for the determination of hepatic triglycerides and total cholesterol concentrations.

Biochemical analysis. Serum aspartate aminotransferase (AST) (27), serum alanine aminotransferase (ALT) (27) and serum total bilirubin (28) were assayed according to their respective previously described methods using commercially available diagnostic kits (Biosystems S.A.). Liver lipid peroxidation end product (malondialdehyde; MDA) was measured by 2-thiobarbituric acid and expressed as nmol MDA/g tissue (29). The concentration of MDA in each sample was obtained from a standard curve prepared from a serial dilution of 1,1,3,3-tetraethoxypropane. Reduced GSH was determined in liver homogenate by enzymatic method using NADPH as a reducing agent and dependent on oxidation of GSH by DTNB, as previously described (30). GR activity was assayed in the liver tissues as previously described (31). Activity of glutathione peroxidase (GPx) was assessed using cumene hydroperoxide as a substrate (32). Assay of 
Table I. Effect of orally administered BPA and/or sesame lignans on the liver function of male rats.

Animal treatment

\begin{tabular}{lrrrr}
\cline { 2 - 4 } Parameters & C-group & \multicolumn{1}{c}{ B-group } & S-group & BS-group \\
\hline Activity of AST (U/l) & $24.60 \pm 1.42$ & $39.43 \pm 1.05^{\mathrm{a}}$ & $17.73 \pm 0.69^{\mathrm{a}, \mathrm{b}}$ & $23.09 \pm 2.77^{\mathrm{b}}$ \\
Activity of ALT (U/l) & $14.66 \pm 0.78$ & $34.92 \pm 0.96^{\mathrm{a}}$ & $5.56 \pm 0.78^{\mathrm{a}, \mathrm{b}}$ & $10.13 \pm 1.12^{\mathrm{a}, \mathrm{b}}$ \\
Total bilirubin (mg/dl) & $0.35 \pm 0.03$ & $0.79 \pm 0.05^{\mathrm{a}}$ & $0.09 \pm 0.01^{\mathrm{a}, \mathrm{b}}$ & $0.27 \pm 0.02^{\mathrm{b}}$
\end{tabular}

Data are presented as mean $\pm \mathrm{SE}$. ${ }^{\mathrm{P}} \mathrm{P}<0.05$ vs. the control group; ${ }^{\mathrm{b}} \mathrm{P}<0.05$ vs. the BPA-treated group. BPA, bisphenol A; AST, aspartate aminotransferase; ALT, alanine aminotransferase; C-group, control group; B-group, BPA-treated group; S-group, sesame lignans-treated group; BS-group, BPA and sesame lignans-treated group.

superoxide dismutase (SOD) based on the ability of SOD to inhibit pyrogallol self-oxidation in alkaline conditions (33). Creatine kinase MB (CK-MB) activity was determined as previously described (34). Lactate dehydrogenase (LDH) catalyzes the reduction of pyruvate by NADH to form lactate and $\mathrm{NAD}^{+}$. This catalytic activity was assayed spectrophotometrically at $340 \mathrm{~nm}$ (35). All biochemical assays were repeated at least three times. The levels of triglycerides (TG), total cholesterol (TC), low density lipoprotein cholesterol (LDL) and high-density lipoprotein cholesterol (HDL-C) were determined using commercially available diagnostic kits (Biosystems S.A.). Very low-density lipoprotein cholesterol (VLDL-C) was calculated from the values of TG, TC and HDL-C using Friedwald and Fredrickson's formula (36).

Histopathological examination. For histological examination, pieces of liver, heart and aorta were fixed in $10 \%$ neutral formalin for $12 \mathrm{~h}$ at $25^{\circ} \mathrm{C}$. The tissue pieces were dehydrated using ascending concentrations of ethyl alcohol and then embedded in paraffin for $2 \mathrm{~h}$ to form blocks. The blocks were trimmed and cut into $6-\mu \mathrm{m}$-thick sections. The sections were de-waxed, hydrated and stained with hematoxylin and eosin, as previously described (37). Stained sections of liver and heart tissue were examined under a light microscope to assess the histological changes. Quantitative analysis of aorta sections was performed using analysis FIVE digital imaging software (Olympus Corporation) and ImageJ (version 1.46r; National Institutes of Health)

Statistical analysis. Statistical analysis was performed using SPSS software (Version 16.0; SPSS, Inc.). Data were presented as the mean \pm standard error. There were 10 rats in each group and each measurement was repeated three times. Comparisons among group mean differences were assessed via one-way ANOVA. Means were then statistically compared using the Least Significant Difference test (LSD). P $<0.05$ was considered to indicate a statistically significant difference.

\section{Results}

Effect of BPA-treatment. As presented in Table I, BPAtreatment caused a significant increase in the activity of serum ALT, AST and total bilirubin compared with the control group. Oral ingestion of BPA (B-group) significantly increased serum levels of TG, TC, LDL-C and VLDL-C compared with the control group $(\mathrm{P}<0.05)$. However, HDL-C levels were significantly decreased $(\mathrm{P}<0.05$; Table II). The accumulation of lipids in hepatocytes was observed in the BPA-treated group via the significant elevation of TG and TC in liver tissue compared with the control group $(\mathrm{P}<0.05$; Fig. 1). Furthermore, BPA treatment caused a significant $(\mathrm{P}<0.05)$ reduction in hepatic GPx, GR and SOD activity, and a decrease in GSH compared with the control group. BPA-treatment also resulted in a significant $(\mathrm{P}<0.05)$ increase in hepatic malondialdehyde (MDA) levels compared with the control group (Table III). In addition, BPA significantly $(\mathrm{P}<0.05)$ increased the activities of serum CK-MB and LDH compared with the control group (Figs. 2 and 3).

The histological analyses performed in the current study confirmed the deteriorating effect of BPA on both the liver and heart tissues. The control group exhibited normal hepatocyte architecture, central vein, blood sinusoids and hepatocytes (Fig. 4). BPA treatment caused hemorrhage in the central vein, loss of the normal hepatocyte architecture, degenerated and vacuolized hepatocytes with pyknotic nuclei, dilation of the hepatic sinusoids and lymphocyte aggregation (Fig. 4Ba and $\mathrm{Bb}$ ). Histological examinations of heart tissues of the control group revealed normal architecture of the myocardial fibers and branching muscle fibers with centrally located oval nuclei (Fig. 5A). The examination of the B-group revealed the loss of the normal muscle fiber architecture, loss of cross striations and fragmentation of sarcoplasm, cardiac muscle cell cytoplasmic vacuolization, connective tissue edema, degenerative changes in myocardial fibers with congested blood vessels and the thickening of coronary branches (Fig. 5Ba and $\mathrm{Bb}$ ). Examination of the dorsal aorta of the control group revealed a normal tunica intima with a single irregular layer of endothelial cells, tunica media with elastic fibers and a normal tunica adventitia (Fig. 6A). BPA-treated rats demonstrated sclerotic changes in its walls, atrophy of elastic fibers, loss of tunica intimal endothelial cells, disorganized tunica media and adventitia, and vacuolation of the tunica media and adventitia compared with normal layers of the dorsal aorta of the control group (Fig. 6Ba and $\mathrm{Bb}$ ). Furthermore, quantitative analysis of the aortic atherosclerotic composition of the B-group revealed a significant $(\mathrm{P}<0.05)$ increase in mean wall thickness compared with that of the control group (Table IV). 
Table II. Effect of BPA and/or sesame lignans on the lipid profile of male rats.

Animal treatment

\begin{tabular}{lcccc}
\cline { 2 - 4 } Parameters (mg/dl) & C-group & B-group & S-group & BS-group \\
\hline Cholesterol & $186.70 \pm 1.58$ & $271.38 \pm 1.00^{\mathrm{a}}$ & $153.33 \pm 1.13^{\mathrm{a}, \mathrm{b}}$ & $212.91 \pm 8.19^{\mathrm{a}, \mathrm{b}}$ \\
LDL-C & $102.68 \pm 3.02$ & $159.04 \pm 5.71^{\mathrm{a}}$ & $72.05 \pm 2.96^{\mathrm{a}, \mathrm{b}}$ & $95.31 \pm 2.46^{\mathrm{b}}$ \\
HDL-C & $39.72 \pm 1.06$ & $12.22 \pm 1.87^{\mathrm{a}}$ & $46.41 \pm 1.79^{\mathrm{a}, \mathrm{b}}$ & $34.79 \pm 1.12^{\mathrm{a}, \mathrm{b}}$ \\
VLDL-C & $32.68 \pm 2.20$ & $73.02 \pm 3.60^{\mathrm{a}}$ & $15.40 \pm 1.24^{\mathrm{a}, \mathrm{b}}$ & $29.82 \pm 1.57^{\mathrm{b}}$ \\
Triglyceride & $163.43 \pm 11.01$ & $365.14 \pm 18.03^{\mathrm{a}}$ & $73.14 \pm 6.13^{\mathrm{a}, \mathrm{b}}$ & $150.28 \pm 7.52^{\mathrm{b}}$
\end{tabular}

Data are presented as mean $\pm \mathrm{SE} .{ }^{a} \mathrm{P}<0.05$ vs. the control group; ${ }^{\mathrm{b}} \mathrm{P}<0.05$ vs. the BPA-treated group. BPA, bisphenol A; LDL-C, low-density lipoprotein cholesterol; HDL-C, high-density lipoprotein cholesterol; VLDL-C, very low-density lipoprotein cholesterol; C-group, control group; B-group, BPA-treated group; S-group, sesame lignans-treated group; BS-group, BPA and sesame lignans-treated group.

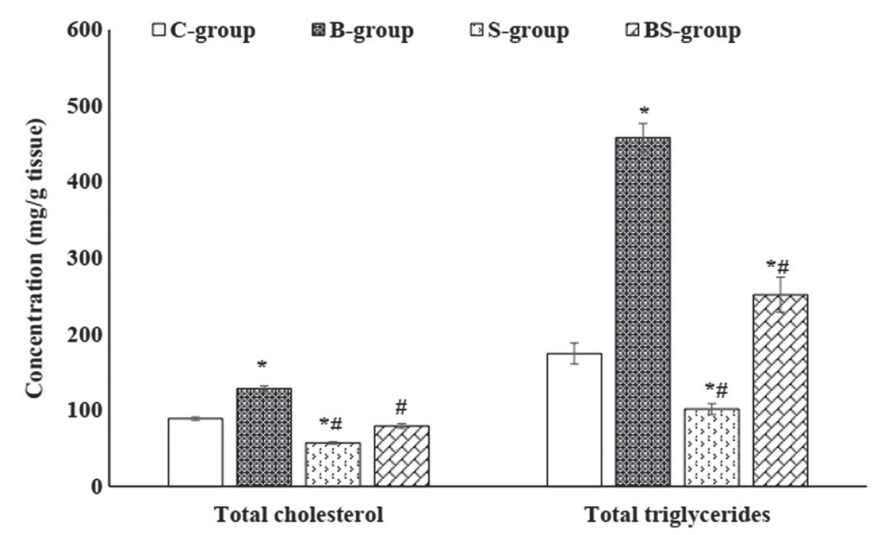

Figure 1. Total cholesterol and triglyceride levels in the liver tissue of male rats in each group. Data are presented as mean \pm standard error. ${ }^{*} \mathrm{P}<0.05$ vs. the control group; ${ }^{\#} \mathrm{P}<0.05$ vs. the BPA-treated group. C-group, control group; B-group, BPA-treated group; S-group, sesame lignans-treated group; BS-group, BPA and sesame lignans-treated group; BPA, bisphenol A.

Sesame lignans attenuates liver function tests. S-group treatment was revealed to improve rat liver function as indicated by the significant $(\mathrm{P}<0.05)$ reduction in the activities of serum AST, ALT and total bilirubin level compared with the B-group. Furthermore, BS-group treatment significantly $(\mathrm{P}<0.05)$ decreased the aforementioned serum parameters compared with the B-group, returning them to levels similar to that of the control (Table I).

Sesame lignans improves lipid profiles. As presented in Table II, it was revealed that $\mathrm{S}$-group treatment significantly $(\mathrm{P}<0.05)$ reduced the levels of serum TG, TC, LDL-C and VLDL-C, and significantly $(\mathrm{P}<0.05)$ elevated HDL-C compared with the C- and B-group. The co-administration of sesame lignans and BPA (BS-group) improved levels of the aforementioned lipid profile parameters compared with the B-group. Furthermore, $\mathrm{S}$-group treatment significantly $(\mathrm{P}<0.05)$ reduced hepatic $\mathrm{TG}$ and TC levels compared with the control group. The results of Fig. 1 also demonstrated a significant $(\mathrm{P}<0.05)$ reduction in hepatic TG and TC contents in the BS-group compared with the B-group.
Sesame lignans ameliorates hepatic oxidative status. As presented in Table III, the results revealed significant $(\mathrm{P}<0.05)$ increases in the activities of hepatic GR, GPx and SOD, and increased levels of GSH in the S-group compared with the control group. Additionally, significant $(\mathrm{P}<0.05)$ increases in the aforementioned antioxidant parameters were observed in the BS-group compared with the B-group. However, MDA levels were significantly $(\mathrm{P}<0.05)$ reduced in the $\mathrm{S}$ - and BS-groups compared with the control group and B-group.

Sesame lignans attenuates cardiac function tests. As presented in Figs. 2 and 3, a non-significant $(\mathrm{P}>0.05)$ change in the serum activity of CK-MB (a cardiac-specific enzyme) was observed in the S-group compared with the control group. However, a significant $(\mathrm{P}<0.05)$ reduction was demonstrated in the serum activity of CK-MB in the BS-group compared with the B-group. In addition, S-group treatment decreased the serum LDH levels to less than that of the control. Furthermore, the activity of serum LDH was significantly $(\mathrm{P}<0.05)$ decreased in the BS-group compared with the B-group.

Sesame lignans improves hepatic and cardiac histological changes. Photomicrographs of control and sesame lignans-treated liver tissue revealed normal cellular architecture with distinct hepatic cells, sinusoidal spaces and central veins (Fig. 4A, Ca and Cb). Furthermore, liver sections of rats treated with sesame lignans in combination with BPA revealed that most of the histological alterations induced by BPA were markedly reduced. The histological changes observed after BPA-treatment were also attenuated from severe to moderate after treatment with sesame lignans (Fig. 4D). Heart sections of the control and sesame lignans-treated groups also demonstrated normal myofibrillar architecture with striations, a branched appearance and continuity with adjacent myofibrils (Fig. 5A and C). Consistent with this result, sesame lignans treatment in the BS-group markedly reduced heart tissue histopathological alterations following BPA exposure (Fig. 5D). Histopathological examination of the dorsal aorta in the control and sesame lignans-treated groups revealed a smooth and continuous intimal surface without lumen irregularities (Fig. 6A and C). Examination of the BS-group dorsal aortas demonstrated a marked reduction in the histological 
Table III. Effect of orally administered BPA and/or sesame lignans on the liver oxidant and antioxidant status of rats.

Animal treatment

\begin{tabular}{lcccc}
\cline { 2 - 4 } Parameters & C-group & B-group & S-group & BS-group \\
\hline MDA (nmol/gm tissue) & $438.80 \pm 11.73$ & $626.80 \pm 35.62^{\mathrm{a}}$ & $223.80 \pm 16.03^{\mathrm{a}, \mathrm{b}}$ & $325.20 \pm 8.96^{\mathrm{a}, \mathrm{b}}$ \\
GSH (nmol/mg protein) & $19.04 \pm 0.96$ & $8.76 \pm 1.12^{\mathrm{a}}$ & $36.57 \pm 2.66^{\mathrm{a}, \mathrm{b}}$ & $23.35 \pm 0.43^{\mathrm{b}}$ \\
GR (mu/mg protein) & $15.01 \pm 0.93$ & $8.72 \pm 0.39^{\mathrm{a}}$ & $17.75 \pm 0.92^{\mathrm{a}, \mathrm{b}}$ & $12.44 \pm 0.76^{\mathrm{a}, \mathrm{b}}$ \\
GPx (mu/mg protein) & $644.75 \pm 20.19$ & $403.72 \pm 11.35^{\mathrm{a}}$ & $838.40 \pm 27.72^{\mathrm{a}, \mathrm{b}}$ & $658.40 \pm 13.41^{\mathrm{b}}$ \\
SOD (U/mg protein) & $4.44 \pm 0.19$ & $2.28 \pm 0.27^{\mathrm{a}}$ & $5.31 \pm 0.32^{\mathrm{a}, \mathrm{b}}$ & $3.68 \pm 0.35^{\mathrm{b}}$
\end{tabular}

Data are presented as mean $\pm \mathrm{SE} .{ }^{a} \mathrm{P}<0.05$ vs. the control group; ${ }^{\mathrm{b}} \mathrm{P}<0.05$ vs. the BPA-treated group. BPA, bisphenol A; MDA, malondialdehyde; GSH, reduced glutathione; GR, glutathione reductase; GPx, glutathione peroxidase; SOD, superoxide dismutase; C-group, control group; B-group, BPA-treated group; S-group, sesame lignans-treated group; BS-group, BPA and sesame lignans-treated group.

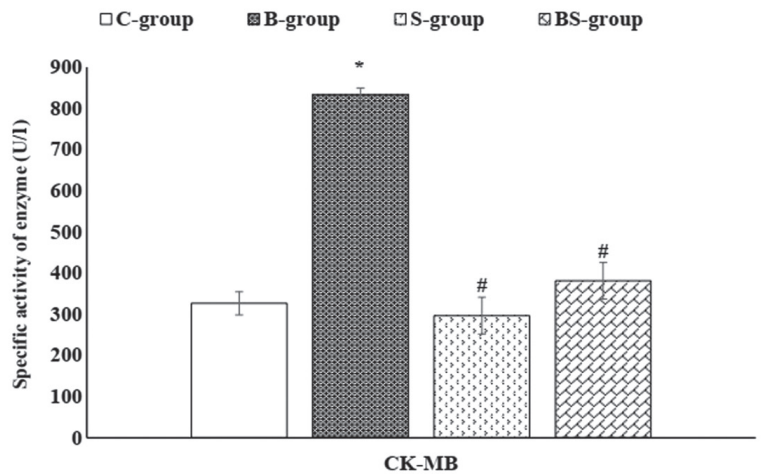

Figure 2. Serum CK-MB enzyme activity in the different study groups. Data are presented as mean \pm standard error. ${ }^{*} \mathrm{P}<0.05$ vs. the control group; ${ }^{*} \mathrm{P}<0.05$ vs. the BPA-treated group. C-group, control group; B-group, BPA-treated group; S-group, sesame lignans-treated group; BS-group, BPA and sesame lignans-treated group; CK-MB, creatine kinase MB; BPA, bisphenol A.

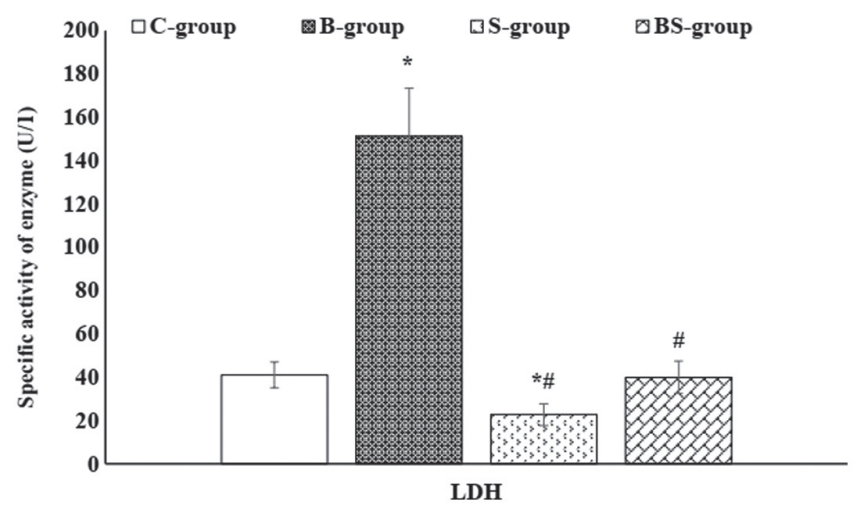

Figure 3. Serum LDH enzyme activity in the different study groups. Data are presented as mean \pm standard error. ${ }^{*} \mathrm{P}<0.05$ vs. the control group; ${ }^{~} \mathrm{P}<0.05$ vs. the BPA-treated group. C-group, control group; B-group, BPA-treated group; S-group, sesame lignans-treated group; BS-group, BPA plus sesame lignans-treated group; LDH, lactate dehydrogenase; BPA, bisphenol A.

alterations induced by BPA (Fig. 6D). The quantitative analysis of S- and BS-group aortic compositions revealed a significant $(\mathrm{P}<0.05)$ reduction in the mean wall thickness of the dorsal aorta compared with the B-group (Table IV).

\section{Discussion}

Previous studies have focused on the impact of BPA on human health and have determined that the toxic effects of BPA may be due to enhanced oxidative stress $(7,8)$. The present study revealed that BPA induced hepatic oxidative stress, steatosis and affects the secretory function and integrity of the liver. Increased levels of hepatic MDA, the decreased activities of GPx, GR and SOD, and the decreased levels of GSH indicated that there were increased levels of oxidative stress in liver cells. These results are consistent with that of Maćczak et al (38) who reported that BPA treatment induces oxidative damage. Another previous study demonstrated that BPA increased lipid peroxidation and decreased the activity of antioxidant defense enzymes produced in rat livers (39). The BPA-mediated reduction of GSH levels may be due to its conjugation with BPA-toxic metabolites and its oxidation to oxidized glutathione (40). Furthermore, certain lipid peroxidation end products [including malondialdehyde (MDA) and 4-hydroxynonenal] are able to alter the activity of mitochondrial enzymes and deplete the glutathione pool (41). Decreased GSH levels may therefore lead to decreased GPx activities (42). Decreased GPx activity is associated with an increased level of the hepatic $\mathrm{H}_{2} \mathrm{O}_{2}$, as well as the direct inhibition of SOD activity (43). It has been reported that BPA reacts with oxygen radicals, decomposing them to various reactive metabolites that have potent oxidant activity (44). These metabolites increase ROS production, inhibit the activity of antioxidative enzymes and increase $\mathrm{H}_{2} \mathrm{O}_{2}$ and thiobarbituric acid reactive substance levels (44). The BPA-mediated increase of ROS may enhance the cleavage of peptide chains and the cross-linking of amino acids in enzymes, leading to the change or loss of enzyme activity (45). Therefore, the mechanism of BPA-induced oxidative damage may be primarily caused by the inhibition of the antioxidant enzyme system, increasing ROS content.

In the present study, BPA induced a dyslipidemic state and enhanced the accumulation of triglycerides (steatosis) and cholesterol in rat liver tissue. These results are consistent with those of Lin et al (46), who demonstrated that BPA induced the intracellular accumulation of fat droplets in a dose-dependent manner. Furthermore, it has been reported that BPA exposure results in hypertriglyceridemia, hypercholesterolemia, changes 

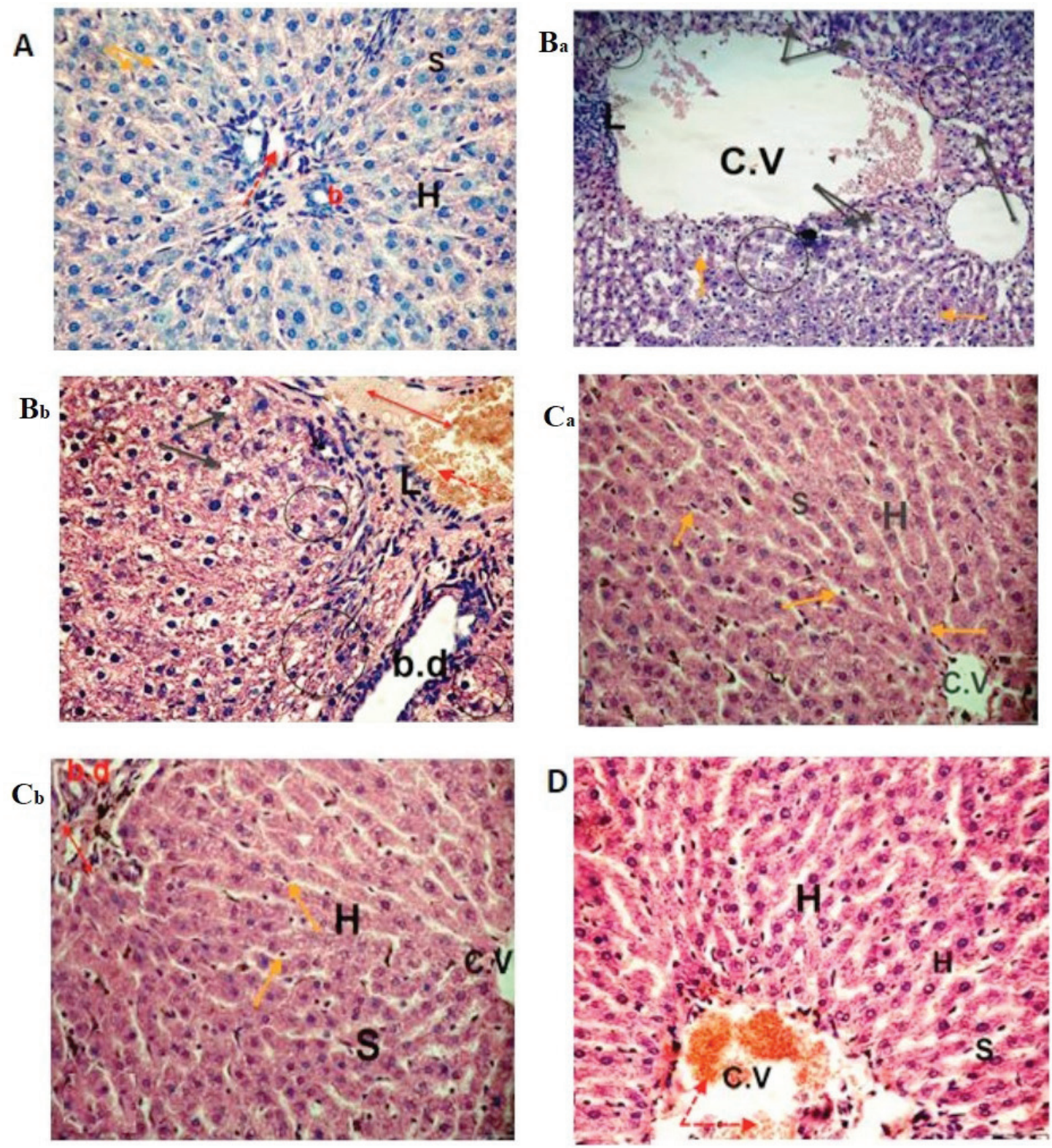

Figure 4. Photomicrographs of liver sections. The (A) control and $(\mathrm{Ca}$ and $\mathrm{Cb})$ sesame lignans-treated group exhibited normal hepatocyte architecture and central vein with normal blood sinusoids and hepatocytes. ( $\mathrm{Ba}$ and $\mathrm{Bb}$ ) Liver sections from the BPA-treated group exhibited distention and hemorrhage in the central and portal vein (red dotted arrow and double headed red arrow, respectively). L, loss of the normal architecture, degenerated hepatocytes with pyknotic nuclei (black circle), vacuolated hepatocytes (black arrows), dilation of blood sinusoids and an increased number of kupffer cells (orange arrows) were also identified. BPA-induced histological changes were markedly reduced in the (D) BPA and sesame lignans-treated group, with moderate improvement in the hepatic cells (H\&E staining; magnification, x400). C.V, central vein; S, sinusoids; H, hepatocytes; BPA, bisphenol A; L, lymphocyte aggregation; b.d, bile duct.

in the composition of fatty acids and the upregulation of genes associated with de novo lipogenesis and cholesterol synthesis in rat livers (47). BPA-induced hepatic lipid accumulation may arise from the increased expression of the transcription factor, sterol regulatory element binding protein-1, which increases the quantity and activity of the enzymes that catalyze lipogenesis, triggering hepatic lipid accumulation (46). The BPA-induced increase of VLDL-C may be due to the increased synthesis and excretion of VLDL-C from liver tissue as a result of the increased hepatic mRNA expression of apolipoprotein B (48). The increased hepatic output of VLDL-C may therefore be a consequence of increased hepatic TG.

BPA-induced oxidative stress and lipid peroxidation has been demonstrated to increase hepatic damage and disrupt the integrity of cellular membranes, leading to leakage of cytoplasmic liver enzymes (49). The present study revealed that BPA caused significant increases in the activities of ALT and AST, and in the level of total bilirubin. These results are congruent with the results of a previous study by Korkmaz et al (50). The results of the aforementioned study revealed that BPA-treatment elevated the activities of ALT, AST and LDH, and caused marked defects in liver morphology. Additionally, Nicolucci et al (51) reported that patients with liver disease exhibit higher BPA levels compared with normal individuals, suggesting an association between BPA-exposure and the health status of the liver. The results of histopathological examination performed in the current study supports those of biochemical experiments. When compared with 

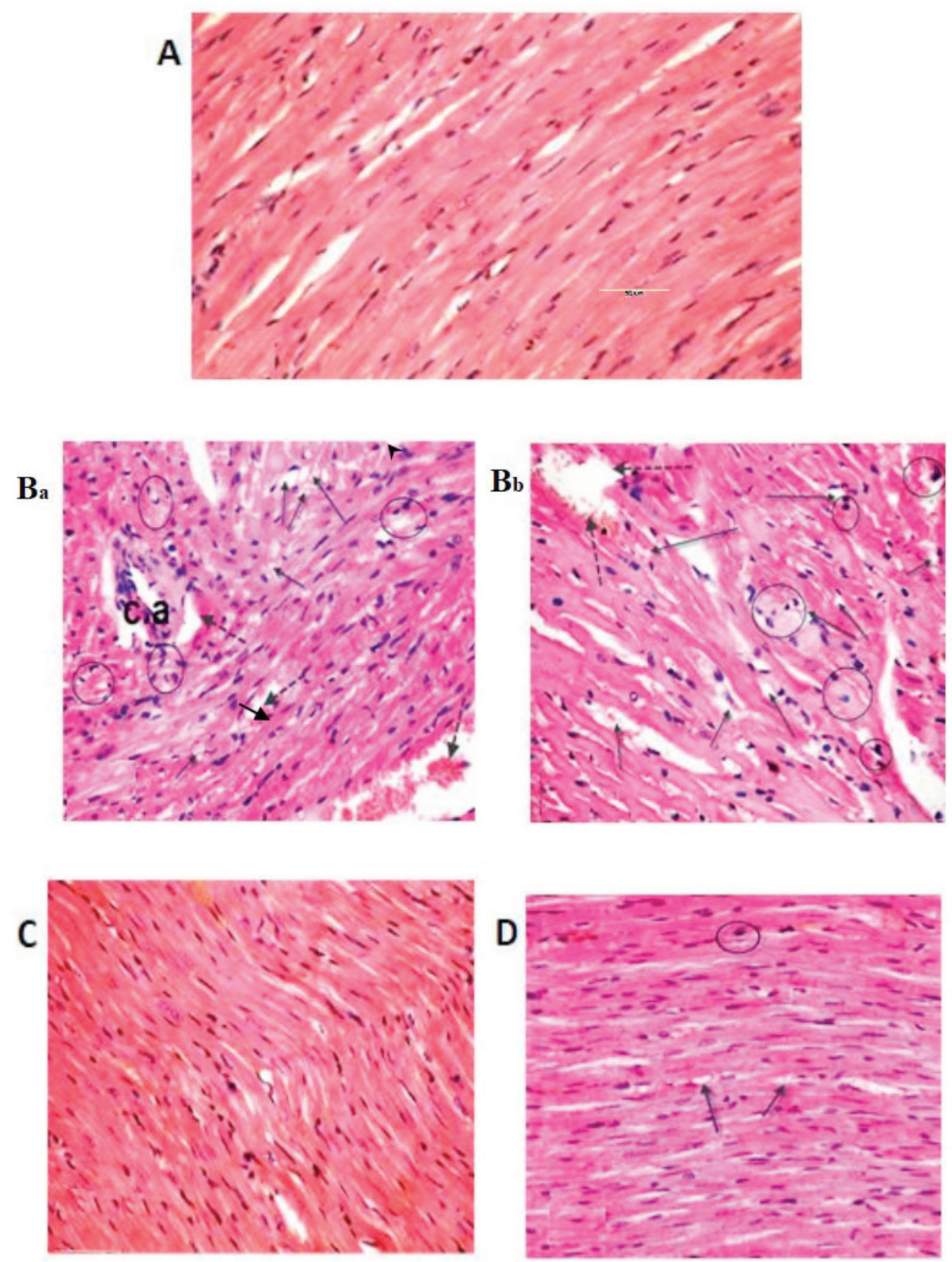

Figure 5. Light micrographs of heart tissue. The (A) control and sesame lignans-treated rats (C) exhibited normal myocardial fiber architecture, with branching muscle fibers and centrally located oval nuclei. ( $\mathrm{Ba}$ and $\mathrm{Bb}$ ) Sections of heart tissue treated with BPA exhibited a loss of normal architecture, widespread fragmentation and muscle fiber degeneration. Inflammatory and mast cells (black circle) were present in the connective tissue, along with a congested blood vessel (dotted arrow), vacuoles (black arrow) and branches of thickened coronary vessels. (D) Histological alterations induced after BPA-treatment were markedly reduced when treated with BPA and sesame lignans (H\&E staining; magnification, x400). BPA, bisphenol A; c.a. coronary artery.

control livers, BPA treatment induced the severe disruption of the liver's architecture, resulting in cellular infiltration, the formation of large cytoplasmic vacuoles and hepatic sinusoids, and an increased number of Kupffer cells. Hepatic lipid accumulation and oxidative stress, followed by liver injury and inflammation, are pathogenic events for non-alcoholic steatohepatitis (52).

The results of the present study revealed significant decreases in the activities of CK-MB, LDH and AST in the BPA-treated group. This indicated that damage or inflammation was present in the heart tissue. Ljunggren et al (53) demonstrated that BPA alters a number of proteins involved in the structural integrity of the myocardial left ventricle. Furthermore, Aboul et al (54) reported that BPA generated ROS and reduced the level of antioxidants in rat heart tissue, which may lead to cardiovascular diseases. A further study demonstrated that BPA inhibited the ventricular function of the heart by elevating ROS in myositis, inducing damage (55). In addition to inducing oxidative stress, BPA increases VLDL-C and LDL-C, and decreases HDL-C, which are considered to be atherogenic indicators. The estrogen-like effect of BPA has a significant effect on cholesterol, which may be the reason for the development of myocardial infarction and other complications such as arteriosclerotic vascular diseases (56). The histopathological examination of rat heart tissue performed in the current study revealed that BPA caused the severe disorganization and degeneration of myocardial fibers, cytoplasmic vacuolization in cardiac muscle and hemorrhages between myofibrils, confirming the presence of damage or inflammation. BPA treatment also induced sclerotic 

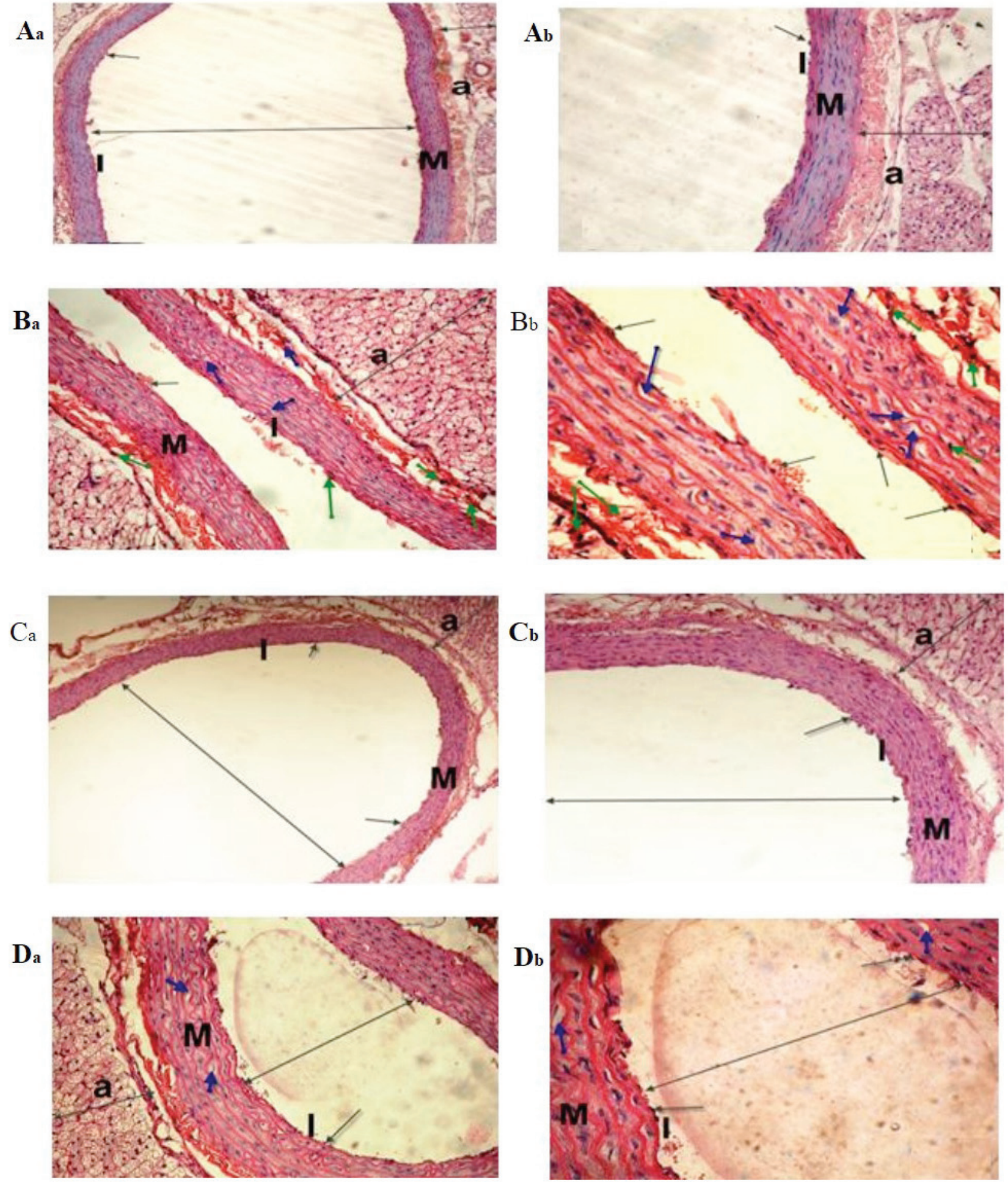

Figure 6. Light micrographs of the dorsal aorta. The ( $\mathrm{Aa}$ and $\mathrm{Ab}$ ) control and $(\mathrm{Ca}$ and $\mathrm{Cb}$ ) sesame lignans-treated group exhibited normal tunica intima with a single irregular layer of endothelial cells (black arrow). The tunica media, comprising elastic fibers and the tunica adventitia also appeared normal. (Ba and $\mathrm{Bb}$ ) The BPA-treated group exhibited sclerotic changes in the walls and atrophy of elastic fibers (green arrows), loss of the tunica intima endothelial cells, disorganized and vacuolation of the tunica media (blue-arrow), increased adventitial thickness and decreased lumen size of the aorta (double-headed arrows) compared with the control group. ( $\mathrm{Da}$ and $\mathrm{Db}$ ) Histological changes induced after BPA-treatment were markedly reduced in the BPA and sesame lignans-treated group (H\&E staining; Aa, Ba, Ca and Da magnification, x200; Ab, Bb, Cb, and Db magnification, x400). I, tunica intima; M, tunica media; a, tunica adventitia.

changes in the walls of the dorsal aorta and atrophy of elastic fibers. This was demonstrated by various changes in the tunica intima and media, including fragmentation, disintegration, vacuolation and a marked increase in thickness. In addition, quantitative analysis of the aortic atherosclerotic composition of the BPA-treated group demonstrated a significant increase in its mean wall thickness, indicating atherosclerotic changes.

The results of the current study indicated that sesame lignans attenuated BPA-induced oxidative stress by decreasing MDA, increasing the specific activities of GPx, GR and 
Table IV. Effect of BPA and/or sesame lignans on the wall thickness of male rat dorsal aortas.

Animal treatment

\begin{tabular}{|c|c|c|c|c|}
\hline Parameter & C-group & B-group & S-group & BS-group \\
\hline Wall thickness $(\mu \mathrm{m})$ & $165.85 \pm 0.34$ & $293.65 \pm 0.26^{\mathrm{a}}$ & $161.50 \pm 0.57^{b}$ & $171.95 \pm 0.68^{\mathrm{b}}$ \\
\hline
\end{tabular}

SOD, and increasing the level of GSH in the livers of S- and BS-group rats. The present study also revealed that sesame lignans supplementation attenuated measured parameters to a level similar to that of the control. This may be due to its free radical scavenging properties. These results are consistent with those of Yashaswini et al (22). The study revealed that sesame lignans increased the activities of GPx and GR, and decreased MDA levels in LPS-treated rats. Furthermore, Ma et al (57) reported that sesamin decreased ROS and MDA production in the liver extract of $\mathrm{CCL}_{4}$-treated mice. The augmented SOD activity induced by sesame lignans enhances the ability of hepatic cells to decompose superoxide anions produced by BPA into $\mathrm{H}_{2} \mathrm{O}_{2}$, preventing further generation of free radicals. $\mathrm{H}_{2} \mathrm{O}_{2}$ is subsequently broken down by GPx, which uses GSH as a reducing agent. Therefore, increasing GPx activity and GSH levels via sesame lignans should protect liver tissue against oxidative damage (58).

In the present study, BPA-induced dyslipidemia and hepatic lipid accumulation were partially or completely attenuated by the co-administration of sesame lignans. Suwimol et al (59) confirmed the results of the current study by reporting that sesame seed powder reduces hepatic total lipid, plasma cholesterol and LDL-C levels in rats. Sesame lignans decreases cholesterol levels by inhibiting its intestinal absorption, increasing its fecal and biliary excretion, and downregulating hepatic 3-hydroxy-3-methyl gluteryl coenzyme A reductase activity (60). The hypotriglyceridemic effect of sesame lignans may be due to the inhibition of lipogenesis, the promotion of fatty acid oxidation and ketogenesis at the expense of its esterification into TG (61). Additionally, sesamin increases fat burning and decreases fat storage by activating peroxisome proliferator-activator receptor alpha (PPAR $\alpha)$, which induces the expression of $\beta$-oxidation enzymes and represses lipogenic enzymes (62). Furthermore, PPAR $\alpha$ activation increases the level of uncoupling proteins, resulting in the expenditure of more calories and fat loss (63). In addition, sesamin has been associated with a reduction of LDL-C and the elevation of HDL-C levels (64). The reduction of leptin is another possible mechanism for the sesame lignans-induced inhibition of hepatic lipid accumulation (65).

The present study revealed that sesame lignans administration exhibits potent hepatoprotective effects against BPA-induced hepatic damage in rats. It improved the secretory function and structural integrity of liver cells by reducing the activities of serum ALT and AST, and reducing the total bilirubin level, producing results that were lower than the control and BPA-treated groups. These results are consistent with those emphasized by Ma et al (57) who demonstrated that sesamin effectively reduced serum ALT and AST, and alleviated hepatic histological changes. The hepatoprotective effects exerted by sesame lignans may be due to their anti-inflammatory effects, as sesamin has been reported to inhibit arachidonic acid synthesis and reduce the production of pro-inflammatory cytokines (66). Furthermore, sesame lignans possess general anti-inflammatory effects as indicated by their ability to reduce C-reactive protein levels (67). The antioxidative effect of sesame lignans and their lipid peroxidation lowering effect contributes to their hepatoprotective effect (17). The hepatoprotective effects exerted by sesame lignans were confirmed following histopathological examination, which revealed that sesame lignans attenuated BPA-induced hepatic alterations. The attenuation of hepatic lipid accumulation (steatosis) and peroxidation by sesame lignans may therefore prevent or decrease the pathogenic events of BPA-induced steatohepatitis.

Sesame lignans protected against myocardial tissue damage by lowering the activity of serum AST, LDH and CK-MB when compared with the control. The protective effect of sesame lignans against myocardial injury may be attributed to the enhancement of certain endogenous antioxidants, including GSH, SOD and GPx (68). Antioxidants have been revealed to attenuate the progression of cardiovascular diseases in clinical trials (69). Furthermore, sesame lignans decreases the risk of cardiovascular diseases by lowering total cholesterol and VLDL-C levels, and elevating HDL-C (70). The histopathological examinations performed in the current study demonstrated that sesame lignans treatment decreased the degeneration and vacuolization of myocardial fibers that were induced by BPA. These results are in line with those by Li et al (71) who demonstrated that sesamin reversed the abnormal changes of the heart and cardiac hypertrophy, and improved myocardial fibrosis. In addition, the morphometric analysis of the dorsal aorta performed in the current study revealed that the histological alterations induced by BPA were markedly reduced by the co-administration of sesame lignans. This was confirmed by the significant reduction of its mean wall thickness, which may further confirm the protective effect of sesame lignans against atherosclerotic plaque deposition in the dorsal aorta. Sesame lignans may be helpful to improve endothelial function and prevent the developments of cardiovascular diseases. The present study had some limitations. The effect of BPA exposure on the degree of liver tissue collagen deposition and on serum levels of troponin I and T should be investigated in future study to confirm its fibrogenic and heart dysfunction effects, respectively. Furthermore, $\mathrm{N}$-acetyl cysteine or vitamin $\mathrm{C}$ should be used as a positive control in future studies and the NF-kB 
signaling pathway should be tested to confirm the protective and antioxidant effects of sesame lignans on hepatic and cardiac tissues.

The results of the current study indicated that sesame lignans attenuated hepatic oxidative stress and protected liver tissue against BPA-induced oxidative damage. Furthermore, BPA-induced increases in serum and liver TC and TG were attenuated by the oral administration of sesame lignans. In addition, sesame lignans restored the liver and heart integrity, as indicated by its ability to attenuate function tests. These results were confirmed by the histopathological examinations. The oral administration of sesame lignans ameliorated BPA-induced histopathological changes in heart and hepatic tissues.

\section{Acknowledgements}

The authors would like to thank the late Professor Ahmed Sobhey El-Sharaky (professor of Biochemistry, Biochemistry Department, Faculty of Science, Alexandria University) for suggesting the idea for this study. The authors would also like the acknowledge Mrs Salma A. Rezk (Pathology Department, School of Medicine, University of North Carolina, USA) for her professional revision of the manuscript.

\section{Funding}

No funding was received.

\section{Availability of data and materials}

All data generated or analyzed in the present study are included in this published article.

\section{Authors' contributions}

SME designed the current study, analyzed and interpreted the data for biochemical analysis in plasma and tissues, and wrote the manuscript. ASAN deigned the experiments and wrote the manuscript. HMA performed and interpreted histological examinations of liver and heart tissues. ASG followed-up animals during the experimental period and performed biochemical analysis. All authors read and approved the final version of the manuscript.

\section{Ethics approval and consent to participate}

The current study was approved by the Institutional Animal Care and Use Committee (IACUC) of Alexandria University (Alexandria, Egypt) in accordance with the guidelines of National Institutes of Health guide for the care and use of laboratory animals.

\section{Patient consent for publication}

Not applicable.

\section{Competing interests}

The authors declare that they have no competing interests.

\section{References}

1. Vandenberg LN, Hauser R, Marcus M, Olea N and Welshons WV: Human exposure to bisphenol A (BPA). Reprod Toxicol 24: 139-177, 2007.

2. Bushnik T, Haines D, Levallois P, Levesque J, Van Oostdam J and Viau C: Lead and bisphenol A concentration in the Canadian population. Health Rep 21: 7-18, 2010.

3. Kang JH, Kondo F and Katayama Y: Human exposure to bisphenol A. Toxicology 226: 79-89, 2006.

4. Vandenberg LN, Chahoud I, Heindel JJ, Padmanabhan V, Paumgartten FJ and Schoenfelder G: Urinary, circulating, and tissue biomonitoring studies indicate widespread exposure to bisphenol A. Cien Saude Colet 17: 407-434, 2012.

5. Zalko D, Jacques C, Duplan H, Bruel S and Perdu E: Viable skin efficiently absorbs and metabolizes bisphenol A. Chemosphere 82: 424-430, 2009.

6. Khalil N, Ebert JR, Wang L, Belcher S, Lee M, Czerwinski SA and Kannan K: Bisphenol A and cardiometabolic risk factors in obese children. Sci Total Environ 470-471: 726-732, 2014.

7. Hassan ZK, Elobeid MA, Virk P, Omer SA, ElAmin M, Daghestani MH and AlOlayan EM: Bisphenol A induces hepatotoxicity through oxidative stress in rat model. Oxid Med Cell Longev 2012: 194829, 2012.

8. Kim JH, Lee MR and Hong YC: Modification of the association of bisphenol A with abnormal liver function by polymorphisms of oxidative stress-related genes. Environ Res 147: 324-330, 2016.

9. Santangeli S, Maradonna F, Gioacchini G, Cobellis G, Piccinetti CC, Dalla Valle L and Carnevali O: BPA-induced deregulation of epigenetic patterns: Effects on female zebrafish reproduction. Sci Rep 6: 21982, 2016.

10. Mohammed F, Abdulwali N, Guillaume D, Tenyang N, Ponka R, Al-Gadabi K, Bchitou R, Abdullah AH and Naji KM: Chemical composition and mineralogical residence of sesame oil from plants grown in different Yemeni environments. Micochem J 140: 269-277, 2018.

11. Hung WL, Lu CH, Liao CD and Hwang LS: Safety evaluation of nano/sub-microsized lignin glycosides from sesame meal [2013]. Food Control 30: 129-136, 2013.

12. Khier MKSE, Ishag KEA and Yagoub AEGA: Chemical composition and oil characteristics of sesame seed cultivars grown in Sudan. J Agric Biol Sci 4: 761-766, 2008.

13. Hsu DZ, Chen KT, Chien SP, Li YH, Huang BM and Chuang YC: Sesame oil attenuates acute iron-induced lipid peroxidation-associated hepatic damage in mice. Shock 26: 625-630, 2006.

14. Sankar D, Sambandam G, Ramakrishna Rao $M$ and Pugalendi KV: Modulation of blood pressure, lipid profiles and redox status in hypertensive patients taking different edible oils. Clin Chim Acta 355: 97-104, 2005.

15. Liu CT and Liu MY: Daily sesame oil supplementation attenuates local renin-angiotensin system via inhibiting MAPK activation and oxidative stress in cardiac hypertrophy. J Nutr Biochem 42: 108-116, 2017.

16. Wan Y, Li H, Fu G, Chen X, Chen F and Xie M: The relationship of antioxidant components and antioxidant activity of sesame seed oil. J Sci Food Agric 95: 2571-2578, 2015.

17. Dar AA and Arumugam N: Lignans of sesame: Purification methods, biological activities and biosynthesis-A review. Bioorg Chem 50: 1-10, 2013.

18. Park SH, Ryu SN, Bu Y, Kim H, Simon JE and Kim KS: Antioxidant components as potential neuroprotective agents in sesame (sesamum indicam L). Food Rev Int 26: 103-121, 2010.

19. Grougnet R, Magiatis P, Laborie H, Lazarou D, Papadopoulos A and Skaltsounis AL: Sesamolinol glucoside, disaminyl ether, and other lignans from sesame seeds. J Agric Food Chem 60: 108-111, 2012.

20. Periasamy S, Liu CT, Chien SP, Chen YC and Liu MY: Daily sesame oil supplementation mitigates ketoconazole-induced oxidative stress-mediated apoptosis and hepatic injury. J Nutr Biochem 37: 67-75, 2016.

21. Zhang $\mathrm{H}$ and Tsao R: Dietary polyphenols, oxidative stress and antioxidant and anti-inflammatory effects. Curr Opin Food Sci 8: 33-42, 2016.

22. Yashaswini PS, Sadashivaiah B, Ramaprasad TR and Singh SA: In vivo modulation of LPS induced leukotrienes generation and oxidative stress by sesame lignans. J Nutr Biochem 41: 151-157, 2017.

23. Reshma MV, Balachandran C, Arumughan C, Sunderasan A, Sukumaran D, Thomas S and Saritha SS: Extraction, separation and characterisation of sesame oil lignan for nutraceutical applications. Food Chem 120: 1041-1046, 2010. 
24. Morgan AM, El-Ballal SS, El-Bialy BE and EL-Borai NB: Studies on the potential protective effect of cinnamon against bisphenol A- and octylphenol-induced oxidative stress in male albino rats. Toxicol Rep 1: 92-101, 2014.

25. Baluchnejadmojarad T, Roghani M, Jalali Nadoushan MR, Vaez Mahdavi MR, Kalalian-Moghaddam H, Roghani-Dehkordi F, Dariani S and Raoufi S: The sesame lignin sesamin attenuates vascular dysfunction in streptozotocin diabetic rats: Involvement of nitric oxide and oxidative stress. Eur J Pharmacol 698: 316-321, 2013.

26. Folch J, Lees M and Sloane GH: A simple method for the isolation and purification of total lipids from animal tissues. J Bio Chem 226: 497-509, 1957.

27. Bergmeyer HU, Herder M and Red R: Approved recommendation (1985) on IFCC methods for the measurement of catalytic concentration of enzymes. Part3. FCC method of alanine aminotransferase. J Clin Chem Clin Biochem 24: 481-489, 1986.

28. Jendrassik L and Gróf P: Vereinfachte photometrische Methoden zur Bestimmung des Blutbilirubins. Biochemische Zeitschrift 297: 82-89, 1938 .

29. Ohkawa H, Ohishi $\mathrm{N}$ and Yagi K: Assay for lipid peroxides in animal tissue by thiobarbituric acid reaction. Anal Biochem 95 351-358, 1979.

30. Griffith OW: Determination of glutathione and glutathione disulfide using glutathione reductase and 2-vinyl pyridine. Anal Biochem 106: 207-212, 1980

31. Smith JK, Vierheller TL and Thorne CA: Assay of glutathione reductase in crude tissue homogenate using 5-5 dithio bis-(2-nitrobenzoic acid). Anal Biochem 175: 408-413, 1988.

32. Paglia E and Valentine N: Studies on the quantitative and qualitative characterization of erythrocyte glutathione peroxidase. J Lab Clin Med 70: 158-169, 1967.

33. Marklund S and Marklund G: Involvement of superoxide anion radical in auto-oxidation of pyrogallol and convenient assay for SOD. Eur J Biochem 47: 469-474, 1974.

34. IFCC methods for the measurement of catalytic concentration of enzymes. Part 7: IFCC method for creatine kinase. JIFCC 1: 130-139, 1989

35. Dito WR: Lactate dehydrogenase: A brief review. In: Clinical Enzymology. Griffiths JC (ed). Masson Publishing USA, New York: pp18, 1979.

36. Friedewald WT, Levy RI and Fredrickson DS: Estimation of the concentration of low-density lipoprotein cholesterol in plasma without use of the preparative ultracentrifuge. Clin Chem 18 499-502, 1972.

37. Drury RAB and Wallington EA: Carleton's histological technique. Oxford University Press, New York, 1981.

38. Maćczak A, Cyrkler M, Bukowska B and Michałowicz J: Bisphenol A, bisphenol S, bisphenol $\mathrm{F}$ and bisphenol AF induce different oxidative stress and damage in human red blood cells (in vitro study). Toxicol In Vitro 41: 143-149, 2017.

39. Abdel-Wahab WM: Thymoquinone attenuates toxicity and oxidative stress induced by bisphenol A in liver of male rats. Pak J Biol Sci 17: 1152-1160, 2014.

40. Bukowska B: Glutathione: Its biosynthesis, induction agents and concentrations in selected diseases. Med Pr 55: 501-509, 2004 (In Polish).

41. Guéraud F, Atalay M, Bresgen N, Cipak A, Eckl PM, Huc L, Jouanin I, Siems W and Uchida K: Chemistry and biochemistry of lipid peroxidation products. Free Radic Res 44: 1098-1124, 2010.

42. Wojnar W, Zych M and Kaczmarczyk-Sedlak I: Antioxidative effect of flavonoid naringenin in the lenses of type 1 diabetic rats. Biomed Pharmacother 108: 974-984, 2018.

43. Soumya R and Vani R: Vitamin C as a modulator of oxidative stress in erythrocytes of stored blood. Acta Haematologica Polonica 48: 350-356, 2017.

44. Vahdati Hassani F, Abnous K, Mehri S, Jafarian A, Birner-Gruenberger R, Yazdian Robati R and Hosseinzadeh H: Proteomics and phosphoproteomics analysis of liver in male rats exposed to bisphenol A: Mechanism of hepatotoxicity and biomarker discovery. Food Chem Toxicol 112: 26-38, 2018

45. Ke C, Liu X, Zuo H, Zhao J, Yang X and Yuan J: The oxidative damage of bisphenol A on the organs of the mice. Sci Res 5 : 1190-1194, 2013

46. Lin Y, Ding D, Huang Q, Liu Q, Lu H, Lu Y, Chi Y, Sun X, Ye G, Zhu H, et al: Downregulation of miR-192 Causes Hepatic Steatosis and Lipid Accumulation by Inducing SREBF1: Nove mechanism for bisphenol A-triggered non-alcoholic fatty liver disease. Biochim Biophys Acta Mol Cell Biol Lipids 1862: 869-882, 2017
47. Marmugi A, Ducheix S, Lasserre F, Polizzi A, Paris A, Priymenko N, Bertrand-Michel J, Pineau T, Guillou H, Martin PG and Mselli-Lakhal L: Low doses of bisphenol A induce gene expression related to lipid synthesis and trigger triglyceride accumulation in adult mouse liver. Hepatology 55: 395-407, 2012

48. Marmugi A, Lasserre F, Beuzelin D, Ducheix S, Huc L, Polizzi A, Chetivaux M, Pineau T, Martin P, Guillou H and Mselli-Lakhal L: Adverse effects of longterm exposure to bisphenol A during adulthood leading to hyperglycaemia and hypercholesterolemia in mice. Toxicology 325: 133-143, 2014.

49. Rönn M, Kullberg J, Karlsson H, Berglund J, Malmberg F, Orberg J, Lind L, Ahlström H and Lind MP: Bisphenol A exposure increases liver fat in juvenile fructose-fed Fischer 344 rats. Toxicology 303: 125-132, 2013.

50. Korkmaz A, Ahbab MA, Kolankaya D and Barlas N: Influence of vitamin $\mathrm{C}$ on bisphenol A, nonylphenol and octylphenol induced oxidative damages in liver of male rats. Food Chem Toxicol 48: 2865-2871, 2010

51. Nicolucci C, Errico S, Federico A, Dallio M, Loguercio C and Diano N: Human exposure to Bisphenol A and liver health status: Quantification of urinary and circulating levels by LC-MS/MS. J Pharm Biomed Anal 140: 105-112, 2017.

52. Periasamy S, Chien SP, Chang PC, Hsu DZ and Liu MY: Sesame oil mitigates nutritional steatohepatitis via attenuation of oxidative stress and inflammation: A tale of two-hit hypothesis. J Nutr Biochem 25: 232-240, 2014.

53. Ljunggrena SA, Igglandb M, Rönnc M, Lindd L, Lindc PM and Karlsson H: Altered heart proteome in fructose-fed Fisher 344 rats exposed to bisphenol A. Toxicology 347-349: 6-16, 2016.

54. Aboul Ezz A, Khadrawy Y and Mourad I: The effect of bisphenol A on some oxidative stress parameters and acetylcholinesterase activity in the heart of male albino rats. Cytotechnol 67: 145-155, 2015.

55. Suthar H, Verma RJ, Patel S and Jasrai YT: Green tea potentially ameliorates bisphenol A-induced oxidative stress: An in vitro and in silico study. Biochem Res Inter 2014: 259763, 2014.

56. Helal EG, Badawi MM, Soliman G, Abdel-Kawi AN, Fadel EA and Abozaid GM: Physiological and Histopathological studies on Bisphenol-A compound as xenoestrogen in male albino rats. Egypt J Hospit Med 50: 127-136, 2013.

57. Ma JQ, Ding J, Zhang L and Liu CM: Hepatoprotective properties of sesamin against $\mathrm{CCl}_{4}$ induced oxidative stress-mediated apoptosis in mice via JNK pathway. Food Chem Toxicol 64: 41-48, 2014

58. Makni M, Fetoui H, Garoui EM, Gargouri NK, Jaber H, Makni J, Boudawara T and Zeghal N: Hypolipidemic and hepatoprotective seeds mixture diet rich in omega- 3 and omega- 6 fatty acids. Food Chem Toxicol 48: 2239-2246, 2010.

59. Suwimol S, Wiroj J, Kewalin W, Natchapon J, Pathamaporn $H$ and Auranun S: Effects of sesame seeds consumption on serum cholesterol and oxidative status in hypercholesterolemia. Food Public Health 2: 193-196, 2012.

60. Asgary S, Kopaei RM, Najafi S, Heidarian E and Sahebkar A: Antihyperlipidemic effects of Sesamum indicum L. in rabbits fed a high-fat diet. ScientificWorldJournal 2013: 365892 , 2013.

61. Kim M, Woo M, Noh JS, Choe E and Song YO: Sesame oil lignans inhibit hepatic endoplasmic reticulum stress and apoptosis in high-fat diet-fed mice. J Functional Foods 37: 658-665, 2017.

62. Penalvo JL, Hopia A and Adlercreutz H: Effect of sesamin on serum cholesterol and triglycerides levels in LDL receptordeficient mice. Eur J Nutr 45: 439-444, 2006.

63. Kushiro M, Masaokab T, Hageshitab S, Takahashia Y, Idea T and Suganoc M: Comparative effect of sesamin and episesamin on the activity and gene expression of enzymes in fatty acid oxidation and synthesis in rat liver. J Nutr Biochem 13: 289-295, 2002.

64. Ide T, Kushiro M, Takahashi Y, Shinohara K, Fukuda N and Yasumoto S: Sesamin, a sesame lignan, as a potent serum lipid-lowering food component. JARQ 37: 151-158, 2003.

65. Fernández-Formoso G, Pérez-Sieira S, González-Touceda D, Dieguez C and Tovar S: Leptin, 20 years of searching for glucose homeostasis. Life Sci 140: 4-9, 2015

66. Chavali SR, Zhong WW and Forse RA: Dietary alpha-linolenic acid increases TNF-alpha, and decreases IL-6, IL-10 in response to LPS: Effects of sesamin on the delta-5 desaturation of omega6 and omega3 fatty acids in mice. Prostaglandins Leukot Essent Fatty Acids 58: 185-191, 1998. 
67. Haider DG, Leuchten N, Schaller G, Gouya G, Kolodjaschna J, Schmetterer L, Kapiotis S and Wolzt M: C-reactive protein is expressed and secreted by peripheral blood mononuclear cells. Clin Exp Immunol 146: 533-539, 2006.

68. Saleem MT, Chetty MC and Kavimani S: Sesame oil enhances endogenous antioxidants in ischemic myocardium of rat. Brazilian J Pharmacogn 22: 669-675, 2012.

69. Conti V, Izzo V, Corbi G, Russomanno G, Manzo V, De Lise F, Donato A and Filippelli A: Antioxidant supplementation in the treatment of aging-associated diseases. Front Pharmacol 7: 24, 2016.

70. Ragavendran P, Sophia D, Arulraj A and Gopalakrishnan VK Cardioprotective effect of aqueous, ethanol and aqueous ethanol extract of Aerva lanata (Linn.) against doxorubicin-induced cardiomyopathy in rats. Asian Pac J Trop Biomed 2 (Suppl): S212-S218, 2012.
71. Li WX, Kong X, Zhanga JX and Yang JR: Long-term intake of sesamin improves left ventricular remodelling in spontaneously hypertensive rats. Food Funct 4: 453-460, 2013.

(c) (i) $\odot$ This work is licensed under a Creative Commons International (CC BY-NC-ND 4.0) License. 